\title{
MOOCS INTEGRATION INTO CAMPUS-BASED CURRICULA: THE CASE FOR RUSSIA
}

\author{
Tatiana Semenova, Ksenia Vilkova, National Research University Higher School of Economics, \\ Russian Federation
}

\begin{abstract}
Massive open online course (MOOC) is a relatively new format of online learning; despite this, it is actively integrated into the educational process of universities. Using data from publications, regulatory documents of universities, official websites of educational institutions, as well as data from expert interviews, this paper summarizes the experience of Russian universities on MOOC integration into campus-based curricula. The main models of MOOC integration into the educational process were highlighted: (a) embedding the MOOC into the blended learning format, (b) replacing part of the offline courses of the academic program with MOOCs, (c) creating an online master's program with MOOCs.
\end{abstract}

\section{Introduction}

Initially, the format of massive open online courses (MOOCs) appeared as part of blended learning technology to replace face-to-face lectures with watching videos outside the classroom with tests and quizzes (Hollands \& Tirthali, 2014b). Leading American universities began to create MOOCs by transforming and transferring their offline courses to an online environment. The practice of integration own MOOCs into the academic program has come along with the practice of buying a license to use the content of MOOCs developed by another university (Sandeen, 2013). Over time, the format of using MOOC in the educational process was transformed: MOOC was used not only as part of blended learning but also as an alternative to traditional courses. Since 2012, the practice of recognizing MOOC certificates has been taking shape, i.e. it becomes possible to get credits for MOOCs. At the same time, there are not only isolated cases of replacing traditional courses with MOOCs (Israel, 2015) but also the embedding MOOCs in the curricula as mandatory ones. Also, universities together with online platforms have started to create academic programs based on MOOCs.

At the moment, the question of the effectiveness of replacing traditional courses with the MOOC, as well as the creation of academic programs based on the MOOC, remains open. Despite this, MOOCs continue to be actively integrated into the educational process in foreign and Russian universities. It is believed that the MOOC integration into campus-based curricula allows applying and refining innovative methods in teaching in practice, improving the students' academic outcomes, bringing the effect of internationalization and co-studying 
from participating in the MOOC with different learners (Sandeen, 2013; Hollands \& Tirthali, 2014a; Belanger et al., 2013; Kizilcec \& Brooks, 2016).

In several studies, the following models of the MOOC integration are highlighted: (a) recognition of credits received for passing the MOOC, (b) purchasing licenses for the content of MOOC created by another university, (c) establishing mutual agreement regarding the credits for the MOOC created by another university for solving a problem with organizing an expertise of courses (Sandeen, 2013), (d) embedding the MOOC into the blended learning format, (e) the use of MOOC as an additional source of knowledge and skills, (f) the use of MOOC for teachers skills development (Chamchiyan, 2014; Makoveychuk, 2015). Due to the fact that the models in these papers were formulated and described four-five years ago, they no longer cover new forms of MOOC integration into campus-based curricula.

In this paper, we identify and describe the existing models of MOOC integration into campus-based curricula based on the research of practices accepted in Russian universities. For the description of the practices, data from publications, regulatory documents of universities, official websites of institutions, as well as data from expert interviews conducted with managers and employees of centres for online education at leading universities in Russia were used.

\section{Models of MOOC integration into campus-based curricula in Russian universities}

The practice of MOOC integration in curricula has not become widespread in Russian universities. However, no legal restrictions were found for the integration of the MOOC into the educational process. Thus, according to the Law on Education, each student has the right to form his educational path. At the moment, three models of MOOC integration into campus-based curricula in Russian universities can be marked:

1. Embedding the MOOC into blended learning format;

2. Replacing part of the traditional courses of the academic programs with MOOCs;

3. Master's programs with MOOCs.

The first model of integration is associated with the use of MOOC content in a blended learning format. Teachers can use materials of MOOCs created by their university, and/or by other universities, including courses in a foreign language, in their traditional courses. There are several options for implementing a blended learning format with MOOCs, each of which will differ in the proportion of offline interaction between the student, teacher and tutor of online learning, as well as the proportion of interaction with MOOC content. For example, students may take a MOOC along with the attending seminars, or students may be exempted from seminars, subject to obtaining a MOOC certificate and passing an offline exam to a university teacher.

The second model of integration - the replacement of part of the traditional courses of the academic program with MOOCs, which can be implemented both at the individual and 
institutional levels. At the individual level, the replacement of the traditional course with a MOOC is an initiative of the student himself. In this case, a student can use not only the MOOC of his university but also online courses from other universities. Instead of a traditional course, students take a MOOC, which they choose from a list of recommended online courses, or independently. The list of recommended MOOCs can be compiled by a separate centre of online education, or academic leader of an educational program, or program manager together with teachers, or methodical committee of departments, or by vice-rector for academic work. When the selected MOOC is not included in the list of recommended, the commission of experts evaluates the characteristics of the course and decides whether to add the course to the list.

The main requirement for getting credits for MOOC is to receive a certificate of MOOC completion with a description of the main characteristics of the course required for the transfer procedure. Also, in most universities, a student has to undergo a proctoring procedure with personal identification in order to eliminate unfair passing of the course. In some cases, a certificate of MOOC completion is a necessary but not sufficient condition: the student also has to pass an oral consultation/exam with the teacher.

At the institutional level, the MOOC is included in the curriculum of the academic program, which students must pass it. The curriculum of the academic program may include MOOCs, developed by the teachers of both their university and another university.

The third model of MOOC integration, which currently exists in Russian universities, is the online master's program. The first online master's program, devoted to the issues of modern combinatorics, was launched in the fall of 2016 in one of the highly selective universities of Russia. The structure of this program has significant differences from the foreign online master's programs. For example, even though the program is implemented online, applicants are required to pass offline written exams in mathematics and computer science. State examinations and the defence of diplomas are held in traditional format too. Also, the number of places per program, and the cost of the program are equivalent to the cost of a traditional (offline) program in combinatorics.

\section{Conditions for successful integration of MOOCs into the educational process of Russian universities}

In our research, we highlight some conditions necessary to ensure the successful integration of MOOCs into the educational process of Russian universities based on data obtained from expert interviews. These conditions can be divided into three groups: (a) staff, (b) administration of the integration process, and (c) functionality of the online platform.

The first group includes university staff, tutors and assistants, who provide support for online learning and track the results of the educational process, as well as those engaged in designing online master's programs consisting of MOOCs from different universities. Participation in the MOOC requires a high degree of independence, time management skills, as well as motivation to complete the course (Onah, Sinclair, \& Boyatt, 2014). If students cannot 
properly allocate their time, if they have any questions during the course (for example, they do not know how to go through the proctoring procedure), then they can contact the online tutor/assistant, who will help to solve emerging problems.

The second group includes conditions related to creating a transparent and flexible system at university, which allows using MOOC as part of the educational process and getting credits for it. Thus, the university should establish a centre that is responsible for administering the process of integrating the MOOC into the curriculum, developing the necessary documents on online learning and concluding agreements on the use of the MOOC of another university.

The third group includes conditions related to the operation of the platform, whose courses are used in the educational process. The online platform should provide a good visualization of studying both for students, who could track their process of learning, and for the teachers, who may receive a quick summary of the course progress among their students.

\section{Conclusion}

The analysis of experience in MOOC integration into campus-based curricula allowed to identify three main models of MOOC integration: (a) embedding the MOOC into blended learning format, (b) replacing part of the traditional courses of the academic program with MOOCs, (c) creating an online master's program with MOOCs. In foreign universities, MOOCs are becoming an integral part of education, creating new conditions for getting an education. At the same time, a regulatory framework already exists in Russian higher education system that allows MOOC integration into the educational process. However, this practice has not gained widespread acceptance. This may be due to the low awareness of both universities and students about the possibility of using the MOOC in the educational process. For example, as was shown in (Balyasin \& Semenova, 2016), every fifth student of leading universities in Russia did not hear anything about MOOC. Also, there is no established practice of integrating the MOOC into the educational process due to lack of necessary information on how to recount the results of the online course, how to organize the process of integrating the MOOC into the curriculum, and how legally and financially solve the issue of its using. However, there are some advantages of MOOC integration into campus-based curricula. First, universities can use the MOOC as training for a specific university life for new students, freshmen. Such MOOCs will allow to incorporate new student rapidly into the university environment, as well as to generate certain knowledge necessary for mastering the disciplines (Firmin et al., 2014; Docq \& Ella, 2015). Secondly, universities can integrate the MOOC in curricula in order to optimize the costs of their educational activities. For example, a university may purchase a MOOC of a famous professor instead of searching for and hiring a qualified teacher. Thirdly, the MOOC integration into educational process allows increasing the variability of the curriculum and expanding the possibilities for creating an individual educational trajectory. And, finally, embedding the MOOC into the educational program may allow improving the educational process, freeing up time for more active practices used at seminars. 
At the same time, despite all the advantages of MOOC integration into campus-based curricula, this practice has its risks. First, the studies have not yet revealed a single standard for organizing a blended format course. Each teacher is faced with the question of constructing a course that combines face-to-face classes and MOOCs (for example, they have to decide, how to correctly combine MOOC content with the content of the traditional course, how to properly allocate time, how to choose a MOOC). Secondly, there is no uniform standard for assessing the quality of the MOOC. The centre for online education and the teacher who plans to use the MOOC should develop mechanisms to assess the quality of the online course. Third, the economic and educational effects of the MOOC integration in university curricula, as well as the business model of online education, are still unclear. Fourth, not all courses can be converted to MOOC format. Also, this format is not suitable for all students, because studies show that the probability of successful completion of a MOOC is higher for those who already have a higher education, online learning experience, and experience on the course subject (Kizilcec et al., 2017; Semenova \& Rudakova, 2016; Goldberg et al., 2015; Hansen \& Reich, 2015; Engle, Mankoff, \& Carbrey, 2015). Fifthly, there is resistance from teachers on the MOOC integration and their low interest in using online courses as part of the curriculum.

However, most of these limitations are removed based on the results of research, which will show (a) how effective the MOOC format is when it is used in educational process of universities, (b) which model is most beneficial both from the economic side and from the maximization of students' academic outcomes, and (c) how evaluate the quality of the course and embed it in the curricula.

\section{References}

Balyasin, M., \& Semenova, T. (2016). Engaging students in online learning. Federal Guide. Education in Russia Moscow, 1, 290-298.

Belanger, Y., Thornton, J., \& Barr, R. C. (2013). Bioelectricity: A quantitative approach Duke University's first MOOC. EducationXPress, 2013(2)

Chamchiyan, A. (2014). To the question of the possibility of using MOOC and the traditional form of education. E-learning in continuing education, 1(1), 339-347.

Docq, F., \& Ella, H. (2015). Why make MOOCs? Effects on on-campus teaching and learning. Proceedings of the European MOOC stakeholders summit, 18-20.

Engle, D., Mankoff, C., \& Carbrey, J. (2015). Coursera's introductory human physiology course: Factors that characterize successful completion of a MOOC. The International Review of Research in Open and Distributed Learning, 16(2).

Firmin, R., Schiorring, E., Whitmer, J., Willett, T., Collins, E. D., \& Sujitparapitaya, S. (2014). Case study: Using MOOCs for conventional college coursework. Distance Education, 35(2), 178-201. 
Goldberg, L. R., Bell, E., King, C., O’Mara, C., McInerney, F., Robinson, A., \& Vickers, J. (2015). Relationship between participants' level of education and engagement in their completion of the Understanding Dementia Massive Open Online Course. BMC medical education, 15(1), 60.

Hansen, J. D., \& Reich, J. (2015). Democratizing education? Examining access and usage patterns in massive open online courses. Science, 350(6265), 1245-1248.

Hollands, F. M., \& Tirthali, D. (2014a). Why Do Institutions Offer MOOCs? Online Learning, $18(3), \mathrm{n} 3$.

Hollands, F. M., \& Tirthali, D. (2014b). MOOCs: Expectations and reality. Full report. NY: Center for Benefit Cost Studies of Education, Teachers College, Columbia University.

Israel, M. J. (2015). Effectiveness of integrating MOOCs in traditional classrooms for undergraduate students. The International Review of Research in Open and Distributed Learning, 16(5).

Kizilcec, R. F., \& Brooks, C. (2017). Diverse big data and randomized field experiments in MOOCs. Handbook of Learning Analytics, 211-222.

Kizilcec, R. F., Saltarelli, A. J., Reich, J., \& Cohen, G. L. (2017). Closing global achievement gaps in MOOCs. Science, 355(6322), 251-252.

Makoveychuk, K. (2015). Prospects of using MOOCs in basic educational programs of higher education in Russia. International Research Journal, 6(37), 66-67.

Onah, D. F., Sinclair, J., \& Boyatt, R. (2014). Dropout rates of massive open online courses: behavioural patterns. EDULEARN14 proceedings, 1, 5825-5834.

Sandeen, C. (2013). Integrating MOOCs into traditional higher education: The emerging “MOOC 3.0" era. Change: The magazine of higher learning, 45(6), 34-39.

Semenova, T. V., \& Rudakova, L. M. (2016). Barriers to taking massive open online courses (MOOCs). Russian Education \& Society, 58(3), 228-245. 